INTERNATIONAL DESIGN CONFERENCE - DESIGN 2018

https://doi.org/10.21278/idc.2018.0235

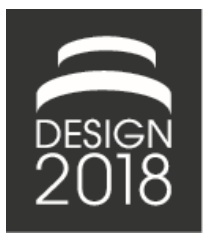

\title{
A QUALITATIVE INVENTORY OF USER INTEGRATION METHODS AND THEIR USAGE IN PRODUCT DEVELOPMENT RESEARCH AND PRACTICE
}

\author{
A. Wallisch and K. Paetzold
}

\begin{abstract}
In the field of human-centred design, user experience (UX) is one of the key factors that make similar products differ in popularity among users. The more holistic one can depict UX, the more specific one can derive product requirements. One promising way to achieve good UX is user integration into product development. However, this is an open concept. By analysing recent research papers, this exploratory study gives some clues to understand the reality of UX research and practice in product development. It turns out that user integration is not necessarily the same as integrating users.
\end{abstract}

Keywords: user integration methods, user experience, user centred design, design methods, design practice

\section{Introduction}

Product development works according to the principle of finality: the product's effect that the engineering designer anticipates is to assist the user in coping with her/his everyday life, to bring her/him pleasure or to support her/him in acting in specific action situations. The moment, the human being becomes the valuation standard, it is necessary to describe her/him in her/his role as user, in order to recognize her/his desires and needs and to align the development activities on them. As an extension of the system boundaries, not only the product has to be considered, but a socio-technical system, which reflects the interaction of the human being in its environment with the product.

In this context, in product development the concept of user experience (UX) is discussed intensively (Bruseberg and McDonagh-Philp, 2001; Hassenzahl, 2010; Garrett, 2011; Zhang et al., 2015). It includes the user with her/his functional and emotional needs, going beyond questions of effectiveness and efficiency, as well as all the effects that a product already has on the user before as well as after use. The concept of UX is therefore characterized as holistic, subjective, situational, dynamic and positive (Hassenzahl, 2008). Since the focus on effectiveness, efficiency and satisfaction in the context of product development is no longer sufficient to meet user needs adequately in product design, in 2010 the concept of UX was defined in the DIN EN ISO 9241-210:2010 "Ergonomics of human-system interaction - Part 210: Human-centred design for interactive systems".

The perceptions, emotions, expectations and reactions resulting from the use of a product or service are clearly focused: "Design is based on an explicit understanding of users, tasks and environments, the users are involved throughout design and development and the design is adopted and refined by usercentred evaluation. The process is iterative, the design addresses the whole user experience and the design team includes multidisciplinary skills and perspectives" (ISO 9241-210). User-oriented design according to the predecessor standard DIN ISO 13407 considered the concerns of potential users only 
in a limited way or as a substitute (ISO 13407:1999). User-centred design according to ISO 9241, on the other hand, requires the user to be actively involved in the design process.

However, this conceptuality does not offer a definitive benefit because even a user-centred design does not necessarily take into account the holistic level of user experience. If the user is only involved at the end of a development step and for evaluation purposes, he ultimately tests only usability. In view of this lack of conceptual clarity, it is hardly surprising that a variety of terminology such as user-oriented, user-centred, user-focused or user-driven are used synonymously in literature and the applying environment (Veryzer and Borja de Mozota, 2005; Kujala, 2008). Even the terminus user experience design (UXD) is lacking analytical precision: as an umbrella term for all processes with which the user's experience can be translated into a product design it subsumes the most diverse perspectives on the user without allowing any conclusions on the actual degree of user integration. Apart from its analytical weakness, ISO 9241 does not provide any concrete process models that can be used to meet its postulate of user integration in all design activities.

With a qualitative analysis of current user-centred design research and practices in the context of product development, the present article aims to reveal the professional interpretation of this common standard. The knowledge of user integration practice is a necessary step towards the continuous improvement of user integration activities and thus towards better UXD. In this sense in the following, user integration is understood as tool to generate good usability and user experience. This study examines the approaches and methods of user integration in different product development contexts and extracts overarching patterns and key dimensions of user integration that provide clues for systematic further development of the research field. In the second and upcoming section, it will briefly describe the origins of UX in order to understand the need for integrating users in engineering design processes. The third section will shed light on different aspects of user integration found in literature. The fourth section will describe the methodology used to conduct the handling of user integration in product development. The fifth section will present the results, successes and limitations of this research. The main outcome is the schematic representation of the findings that allows both, a systematic classification of the identified issues and the identification of further research needs. Finally, the main dimensions guiding through the conceptual diversity of user integration will be discussed and a further research agenda will be outlined.

\section{Designed for interaction: It is impossible to not experience a product}

The term User Experience was firstly used to describe all aspects of a person's experience with a system (Norman et al., 1995). The concept is widely used, but understood in different ways. Different definitions and models have been proposed (Hassenzahl, 2003; Karapanos et al., 2010) without resulting in a true consensus. One of the three pillars of the UX manifesto published in 2007 consisted in answering the question "What is UX?" (Law et al., 2007), by studying the basic concepts and assumptions related to UX. Today, this is mostly done by following two main approaches: reviewing UX research (Law et al., 2014) and surveying UX professionals (Law et al., 2009). In major UX models, the usability concerns for effectiveness and efficiency were included as "pragmatic" or "instrumental" qualities of a system, whereas the notion of satisfaction has been extended to the one of "hedonic" system's quality (Hassenzahl, 2003; Mahlke, 2008). Despite sharing many grounds with the concept of usability, UX expands it by including emotional, subjective and temporal aspects involved in the interaction. While the concept of usability mainly focuses on an objective approach of the interaction, UX is also exploring subjective factors characterizing the experience between human and technology. However, usability concerns are generally included as parts of UX, reflecting the "pragmatic" aspects of the interaction. On the other hand, UX-related factors like aesthetics or hedonic qualities might even significantly influence perceived usability (Thüring and Mahlke, 2007).

At a generic level, the research community agrees that UX as a phenomenon designates the experience of using an interactive system. Based on the literature, one can assume this experience unique to an individual and influenced by several factors, encompassing prior experiences and expectations based on those experiences (Hassenzahl, 2008). The social and cultural context of the interaction also plays an important role by affecting the felt experience: "UX may change when the context changes, even if the system does not change." (Roto et al., 2011, p. 10). 
Interestingly, a replication study done by Lallemand et al. (2015) recently revealed that Industry less agrees on the uniqueness of lived experience than Academia, which means that professionals tend to believe more in the comparability of people's experiences than academics. Surprisingly, it is rather in Industry that one considers UX should be addressed in a qualitative manner (Lallemand et al., 2015). There is another difference: According to the study, the most experienced practitioners feel less need for a standardized definition of UX. It seems that with progressing experience and increasing integration of UX to business processes, experts have developed their own understanding of this concept and do not need a shared view on this topic anymore.

A standardized UX definition would in fact mostly contribute to communicate on UX, to teach this concept and to progress in this field of research. An agenda for UX research and practice has been published in 2010 (Law and van Schaik, 2010) and focuses primarily on the need to model UX. The results from the replication study mentioned above (Lallemand et al., 2015) however suggest that this concern is more relevant to Academia. UX professionals are designing systems or products meant to trigger a specific type of experience but they are not designing the experience itself. As "user experience goals $(. .$.$) are concerned with how users experience an interactive product from their$ perspective rather than assessing how useful or productive a system is from its own perspective." (Preece et al., 2002, p. 19), the need to integrate the user's perspective into product development processes becomes obvious.

\section{User integration or gathering information about him?}

User integration, which is interchangeably named user involvement or user participation, has the potential to improve the quality of the system by providing a more complete assessment of user information requirements (Cavaye, 1995; Carroll and Rosson, 2007). Therefore, it is considered as an important factor that influences implementation success or failure (Bosman, 2005). There are mixed results concerning whether the involvement of users makes a product or a system more useful (Hartwick and Barki, 1994) but it has been demonstrated to correlate with user satisfaction (McKeen et al., 1994). Likewise, it can has positive effects in the future usage of a product.

Research in this context seeks for methods with which people as users can be integrated into the development process in a targeted way by making use of their experience and knowledge for product development. As a theoretical framework for integrating knowledge and expectations of the users into product development processes, user integration causes a densification of product-relevant users and their usage context. The aim of doing so is to ensure the identification and prioritization of the use cases and product requirements from the user's perspective. However, this does not allow any statements on the quality of the integration of the user. This can be done in a more passive way, for example in the case of a standardized survey, as well as active, for example if the user itself gets part of the development team. The nature of the integration depends significantly on the objective of user integration. This is not only a question of the extent to which the user's life and action situation is depicted, but also what results can be expected. Even during the active participation, the user's opinion on the development task is manipulated. It remains open to what extent this opinion forming has an impact on the results of the development and evaluation.

User integration in terms of activities engaged by users does not provide a complete and accurate picture, because there are many different ways in which users can play a part in product development (Lin and Shao, 2000). User participations vary in terms of type, degree, content, extent, and formality. The user's impact can contribute to different roles they can take over in the design process (Damodaran, 1996; Fichter 2005).

In user participation area of study, communications between users and designers have recently been an interesting debate (Limpornpugdee et al., 2009). It is widely agreed that effective communication plays an important role during user participation in predicting the success of the outcome whilst the ineffective communication had a negative effect on the success (Böhmer et al., 2014). It is evident that the communication between users and engineering designers has a direct positive impact on user satisfaction. It remains open how this can be taken into account when the user's integration into product development only happens by mental models that the engineering designer presumes. 
The statements of the users need to be interpreted by the engineering designer, so practical knowledge of the developers of the product as well as of the typical user is of great advantage. However, a validation with regard to the user's wishes is also required. User-centred designers need to engage with potential users directly, assuming that understanding the details of the experiences of individuals give greater insight in their habits and behaviour. Interactions with users in the early stages of development go beyond simple needs identification. Studies have found the importance of having users involved closely in design and development. Several works have discussed that frequent and intimate user involvement is important for improving product concept, as well as for improving innovation capabilities and product market performances (Cooper and Kleinschmidt, 1987; Kim and Wilemon, 2002; Lilien et al., 2002).

The perspective on the users has changed over time. Nowadays, they are requested to take over different roles in the user participation process (Olsson, 2004; Fichter, 2005). User involvement can be beneficial but there are also several challenges: access to users, little consensus across users, users unaware of implementation constraints, and a user's lack of understanding the design process and of what developers need to know (Wilson et al., 1997; Kujala, 2003). Meixner (1995) investigated the influence of user participation on product quality by comparing the evaluation of product designs, which were made by a pure design team and a participatory team. He observed that users tend to take over no responsibility for the designs and hardly make their own proposals. They could not meet the expectations that was made regarding their creativity. Additionally, the designers were having trouble implementing the user comments adequately.

Requirements on user interfaces can also originate from several sources other than the user, e.g. regulations and safety requirements that must be incorporated in addition to user's needs. Here, the borderline between real user insights and object knowledge becomes blurred. The user develops his or her own interpretation of certain requirements, which are integrated into a subjective evaluation mesh with corresponding decisions for action. Nevertheless, there is a risk that the strength and weakness analysis of a product idea is based on ratings of stereotypes, prejudices and placeholders instead of real user perspectives. This leads to the question what actually happens in research and practice when it comes to user integration. Which mindsets do users and designers follow, and how are they dealing with their different competences and expectations to collaboration? What are the dominant methods of user integration and how far do they lead to new challenges? The present explorative study is intended to help to approach these questions by uncovering the interrelationships that are central for answering. Only when these can be explained and understood, problem-appropriate models of action can be derived.

\section{Analysis of current user integration practices}

For analysing the user-centred design practice in the context of product development, conference proceedings serve as a fruitful data source. The wide range of conference contributions enriches the subject by insights of different disciplines; the homogeneous subthemes ensure the comparability of the single papers. The self-selection into this investigation, which happens by the paper submissions, in this case serves the research strategy: following the requirements of qualitative methodology, the focus is on the recognition of essential and typical relationships (Flick, 2009). One can assume that those disciplines and professionals, which are particularly concerned with the user-centred design research, are also the ones that decisively influence the UX and user integration standards. Of course, this research approach does not allow controlling either the absolute coverage of the field's perspectives or the relative coverage with regard to the target population. Nevertheless, it allows getting an idea of international research trends.

\subsection{Data base}

On the one hand, the narrative density of the data material is anticipated proportional to the reputation of the conferences and on the other hand, the reliability of the data as proportional to the narrative density. Therefore, the database here consists of the conferences ICED 2015, DESIGN 2014 and ICED 2013. A frequency analysis of the terms user experience (UX), user-oriented, user-centred (-centered) and user integration (-participation, -involvement) identified 114 papers with a myriad of sources. The 
decision for the search terms was made due to their synonymic use. After eliminating footnotes, references and acknowledgements without reference to the subject, the sample to be analysed comprises 102 proceedings. In order to secure the trend analysis beyond the engineering sciences, comparative data were used in the form of UX-relevant conference proceedings of all specialist disciplines listed in SCOPUS database during the investigation period.

\subsection{Data processing}

For descriptive statistics, the identified proceedings were entered into a database containing keywords, subject discipline, research perspective, analysis level, frequency data and the case example. For the core piece of the study, the qualitative analysis of the research practice within the field, a text file with all sources, which are sequenced in an unformatted solid text, was created. Without any reference to the authors, their professional background and their explicit questioning, the inner logics of the individual contributions gets broken with its text structure and therefore, overlapping structures in the field can be identified and the underlying relevance structures can be revealed. The analysis was done by using MAXQDA, a professional software for qualitative, quantitative and mixed methods data analysis that relies on traditional methods of analysis, such as those used in grounded theory.

\subsection{Doing grounded theory}

Grounded theory is less a theory than a research strategy in order to discover a theory based on empirical, mostly qualitative, data (Glaser and Strauss, 1967). One can speak of a methodology for the development of a data-anchored theory. It includes a coordinated arsenal of individual techniques, with the aid of which interviews, field observations, documents and statistics can gradually be used to develop a theory based on data. The theoretical foundation of the grounded theory is symbolic interactionism. This origin is based on the fundamental assumption that human activity and human interactions are at the centre of research, and that action and interaction are determined not by physical environmental stimuli but by our symbol-mediated interpretations. While reviewing theories focuses on the logical conclusion of deduction, grounded theory requires a steady change between induction and deduction.

While coding is more inductive in the beginning that is from the data to concepts, in the course of arranging the found theoretical concepts and their relationships to one another it is often helpful to following a coding scheme: from a higher concept back to the data or data-generated concepts, which ultimately condensing in a conceptual network. Coding describes the process of selecting part of the data material, for example a paragraph or one part of an image and assigning a code to it. In the context of qualitative research, a code is more of a label used to name phenomena in a text or an image. Codes can possess different meanings and take on different functions in the research process: there are factual codes, thematic codes, theoretical codes and many more (Richards, 2015). From simply looking at the code itself, its role in the research process is not always clear: it could be of minor importance or play a key role. Only its context or framing will shed light on that.

\section{Results}

This chapter will provide the reader with a linear description of the main results of the research. The presentation of the results is organized according to the research steps done: firstly, a brief descriptive analysis of the database will be given. This is followed by an overview of the classification revealed from the database. In the subsequent section, the study's main outcomes of a topic-based analysis, in order to understand better how user integration is perceived and implemented, will be shown. Finally, some remarks will be made on challenges and limitations of the analysis.

\subsection{Descriptive analysis}

The analysis confirmed that the field of user experience is continuously increasing, influenced, and shaped by various different disciplines, e.g. mechanical engineering, industrial design, human computer interaction, product development and commercial design. Main topics are user integration (30\%), design theory and research $(28 \%)$, methodology $(17 \%)$, product development case studies $(17 \%)$ and other 
(8\%), which includes e.g. education, human object interaction, and user interface. A comparative analysis on SCOPUS showed very similar results: Over the last 10 years, user experience gained rising awareness in different disciplines and the keyword mentioned, while its origin, HCI, both as discipline and research topic lost its previous aegis.

Researchers frequently use empirical studies to examine the integration of users' experiences into the different phases of product development $(90 \%) .38 \%$ were qualitative, while researchers used quantitative methods in $23 \%$ of the cases and combined approaches in $39 \%$ of the cases. Most studies were observational in nature, which can be explained by the strict definition of interventional studies. There were more non-comparative studies (89\%) than comparative studies $(11 \%)$. There were slightly more studies conducted in a natural setting than in a contrived setting, although the significant number of studies where the setting was unspecified can skew the result.

The analysis showed that $30 \%$ of the studies conducted interviews, $27 \%$ used observation, $26 \%$ collected documents and 10\% did experiments (including simulations and measuring sensorial data) to collect user data. The term interview subsumed semi-structured, ethnographic, baseline interviews as well as questionnaires. Documents encompasses anything from sketches to protocol logs and (online) product reviews. Simultaneous verbalisation and introspection were the least frequently used data collection methods $(4 \%$ and $3 \%)$. Simultaneous verbalisation is not natural and participants have to be trained in it, introspection is time-consuming and requires discipline and motivation on the part of the participants, which cannot be guaranteed. Social media based user diaries seem to be a promising process improvement.

Observation and collecting documents complement each other because observation is a real-time, continuous method and takes place parallel to the study while collecting documents is retrospective. Observation can provide context to the data present in the documents collected. Late stage and collaboration studies were conducted predominantly in a natural setting with real tasks. Empirical studies on early stages and concept generation tend towards a contrived setting with realistic tasks. Few empirical studies in the stage of concept generation use real-time data collection methods.

One major finding is the discussion of user integration in the different development phases. While on the one hand, the importance of integrating users into the early stages of product development is well documented; most studies, on the other hand, deal with users in their role as evaluator. This implies they are evaluating and modifying already existing product ideas and products, which means they are not actually integrated in the early development but rather its finalization.

As a general outcome, there is a lack of standardized documentation in empirical studies. Besides that, the lack of naming of the evaluation methodology must also be criticized. Both deficiencies make comprehension and evaluation of the results more difficult; therefore, the analytical levels cannot always be understood clearly.

\subsection{Classification system}

From the data material, various analysis levels of user experience research can be condensed in the context of product development. In addition to user experience as theoretical research topic, also methods with which the user experience is to be recorded are made subject of discussions and evaluated concerning their practical applicability. Investigations on the user experience design as result of user experience surveys address the question of how the collected data can be used to create an adequate user experience, and finally, on a higher abstraction level, research on user experience as research field is done. These levels of analysis can be condensed into four theoretical concepts: user experience design, data gathering user experience, user integration in design and product development practice.

To understand more easily how the following conclusions are derived, Table 1 presents the codings, including subcodes and their main segments. It is worthwhile noting that the subcodes include more segments as shown above (Table 1). They have been aggregated just in the case of reliable data density. Considering the page restrictions, in the following just the coding for the main theoretical concepts will be presented briefly. 
Table 1. Overview of the codings

\begin{tabular}{|c|c|c|c|}
\hline $\begin{array}{l}\text { Theoretical } \\
\text { Concept }\end{array}$ & Code & Subcodes & Segments \\
\hline \multirow[t]{6}{*}{$\begin{array}{l}\text { User } \\
\text { Experience } \\
\text { Design }\end{array}$} & \multirow{6}{*}{$\begin{array}{l}\text { Methodological focus } \\
\text { on UXD, helicopter } \\
\text { perspective, academic } \\
\text { discussion, generic } \\
\text { evaluation of methods } \\
\text { and tools used in } \\
\text { product development } \\
\text { practise, UXD } \\
\text { challenges for product } \\
\text { development on a } \\
\text { theoretical level }\end{array}$} & Design Methods & $\begin{array}{l}\text { Emotional design/ empathic design/ } \\
\text { inclusive design/ interaction design/ } \\
\text { Kansei design/ participatory design/ } \\
\text { service design }\end{array}$ \\
\hline & & Research on UX(D) & Theory development \\
\hline & & Methods and Tools & $\begin{array}{r}\text { Modelling/ expression/ analysis } \\
\text { methods and tools }\end{array}$ \\
\hline & & UX data translation in UXD & Limitations \\
\hline & & Education & Training \\
\hline & & Development phases & \\
\hline \multirow{13}{*}{$\begin{array}{l}\text { Data } \\
\text { Gathering } \\
\text { User } \\
\text { Experience }\end{array}$} & \multirow{13}{*}{$\begin{array}{c}\text { Summary and } \\
\text { discussion of different } \\
\text { methods regarding } \\
\text { their usefulness for } \\
\text { specific questions, new } \\
\text { method development, } \\
\text { social science methods } \\
\text { integration and } \\
\text { adaption, mainly } \\
\text { focusing on an action } \\
\text { level }\end{array}$} & Research logic & $\begin{array}{r}\text { Qualitative/ quantitative/ field/ } \\
\text { laboratory }\end{array}$ \\
\hline & & Restrictions & Measuring errors/ data access \\
\hline & & Interview & Face-to face/ survey/ narrative \\
\hline & & Observation & Process-/performance-oriented \\
\hline & & Online reviews & \\
\hline & & Case study & \\
\hline & & Documents & \\
\hline & & Focus groups & \\
\hline & & Mixed methods & \\
\hline & & Experiment & \\
\hline & & Physiological measures & \\
\hline & & Cultural probes & \\
\hline & & Think aloud & \\
\hline \multirow{8}{*}{$\begin{array}{l}\text { User } \\
\text { Integration } \\
\text { in Design }\end{array}$} & \multirow{8}{*}{$\begin{array}{l}\text { Role of users in } \\
\text { product development } \\
\text { processes, integration } \\
\text { by gathered data or } \\
\text { participation, } \\
\text { identifying and } \\
\text { separating stereotypes } \\
\text { and mechanisms of } \\
\text { inclusion/exclusion }\end{array}$} & Definitions & Human-centred/ user-centred \\
\hline & & Designer-user relation & $\begin{array}{l}\text { User/ designer/ collaboration/ lost } \\
\text { in translation/stereotyping/ expert }\end{array}$ \\
\hline & & User needs & User-/expert-driven \\
\hline & & User descriptions & Subjective/objective \\
\hline & & User groups & \\
\hline & & User centring methods & \\
\hline & & Indirect integration & Active/passive \\
\hline & & Failures & \\
\hline \multirow{5}{*}{$\begin{array}{l}\text { Product } \\
\text { Development } \\
\text { Practice }\end{array}$} & \multirow{5}{*}{$\begin{array}{l}\text { Meaning of UXD as } \\
\text { starting point for } \\
\text { product development } \\
\text { in a very broad } \\
\text { context, external } \\
\text { factors, relations and } \\
\text { explanations why } \\
\text { people choose products }\end{array}$} & Critical success factors & $\begin{array}{l}\text { Market conditions/ usage context/ } \\
\text { product-based/ application areas }\end{array}$ \\
\hline & & Technology acceptance & \\
\hline & & UX approach & \\
\hline & & Interdisciplinary concepts & \\
\hline & & Challenges & \\
\hline
\end{tabular}

User experience research differs on two analytical levels: on the one hand, there is the (practical and scientific) research area in which the user experience is collected and studied. On the other hand, the field of user experience research itself, with its perspectives and questions, is scientifically explored on a meta-level. This is reflected in the division between user experience design, which is coded as the more abstract scientific area, and product development practice, which is coded as the area where UX data is collected under different viewpoints. In this context, market, context and product dependency 
and usage situation are discussed as well as various characteristics of the human-product interaction are described and processed. Product development is not merely connected with a product's commercial success or failure but as well with its social acceptance, its availability, accessibility, affordability and accountability, for both the producer and the user.

Therefore, a central topic is the question of how the user and her/his needs can be described, which is coded as data gathering user experience. Various survey methods are used to capture the desired UX data under various conditions. Particularly, social science concepts are increasingly used. However, it is rarely disclosed nor justified which higher-level research concepts require the use of certain methods. Partly the impression is given that some methods, regardless of their fit, are used for questioning and thus squander away their potential. Increasingly, qualitative methods are used, whereby it often does not seem quite clear how the abundance of collected data should ultimately be dealt with. Data collection methods are comprehensively described, while data evaluation methods receive little attention. Possibly this impression arises from a lack of appropriate research documentation. The safe application and of the methods and utilization of the gained data depends obviously on different product groups, perspectives on the user in her/his or her roles and the level of training in dealing with the methods. In summary one can say, there is more systematization needed.

The question, how the collected data now can be used to create product that exactly fit the user needs, is coded as user integration in design. It aims bridging the gap between the differing mental models of the user and the designer (the conceptualisation that the designer has in mind). Works related to this concept investigate various fail and success factors of positive user experience as well as the different roles of the user, in the utilization as well as in the design process. The perspective on the user has changed over time from a passive to an active role, which must be further differentiated: she/he meets us as user, end-user, consumer, prosumer, customer, designer, and co-user and expects a holistic usage experience over the entire time axis of product usage. The product developer now has to find out how the qualitative user perspective can be translated into technical specifications. There is a gap between the explicit terms and the implicit terms of requirements. There is a need for using terms that mean the same to users, designers, engineer and other stakeholders. Further work needs to be done on the commonalities and differences of the language of users, designers, engineers and other stakeholders.

Coded as user experience design, scientific research on different design approaches, concepts and methods addresses scientifically the close interactions between people and objects in real and daily life. Different frameworks like for example, emotional design, inclusive design, etcetera, highlights the strong need for user centring in all design activities. These frameworks are not juxtaposed one another in a holistic way but rather most works emphasize the advantages of the respective key category. Although these can make certain aspects of the user experience accessible to the UX design process, but do not offer valid process models to it either. It seems as if user-centred design itself, acting on different levels with different tools, lead to the disciplinary and theoretical fragmentation that hinders a reliable total concept of user experience. However, the analysed works show up with a wide range of awareness of user integration as leading topic in product development. Thus, further research was done to identify key interrelationships in order to gain a better understanding of the ways in which practical user integration is actually implemented.

\subsection{Topic-based analysis}

At the theoretical level, UX relies on several disciplines, for example psychology, cognitive science, but also usability engineering. Action theory has outlined a comprehensive view of user experience as a complex and socially situated phenomenon where technology acts as a mediator between the user and the activity. Pleasure and emotions generated by the use of products or technical systems, and even the satisfaction of basic needs through technological interactions are major topics within the field of UX. Researchers and practitioners agree that UX is the result of the interaction between three elements: the user, the system and the context.

\subsubsection{Aspects of user integration}

The study shows that engineering designers are aware of users as having different roles in the design process: informative, consultative and participative. The roles object for observation, information provider 
and contributor of ideas covered the informative form. The roles advisor, examiner, and tester cover the consultative task, for example users trying a prototype. Finally, the roles designer and decision maker belong to the participatory form where users have more influence on the final product. On the other hand, designers see users predominantly involved as examiners and testers and do not want them to be designers or decision-makers. They justify it with the fact that users often hold different opinions about the design. One possible reason for this impression could be the inadequate communication basis of both groups. However, the imbalance implies that the way in which the user data is collected is already structured by the developer's perspective. This means that the user's perspective is lost for the early stages of product development, which on the other hand are relevant for sustainable product success. Therefore, investments should be made in kick-off events with the aim of creating a common thinking and language base.

Access to the users is often seen as challenge, probably because the users are normally not found within the developing organization but have to be recruited from outside. It is important that they are somehow informed users, understanding when decisions will be made and the consequences of them. However, when highly skilled and specialized lead users take part as user representatives, there can be a risk that the design will be optimal for highly informed users, not the average ones. Regarding the user data gathering, observation is the preferred method, which designers want to get more access to it. This correlates with the statement that users preferably are integrated as testers. Just interaction with an already existing object can be observed. Product development could benefit from observing the interaction with predecessor products in order to generate new product ideas from them and develop them interactively with the user. Instead of just having product ideas evaluated, users should be qualified to develop their own ideas that are evaluated by the engineering designer. This of course requires an understanding of the design process and feasibility criteria.

There are powerful approaches to examine user insights, as for example using narrative stories as communication tool. However, to gain the full range of insights, it is needed to change the perspective on the usage of these stories. If they are merely based on assumptions of engineers, the user's possibilities for active contribution are limited. The first obstacle to user integration in many design situations is apparently obtaining management consent that real users should be involved. However, one has to be aware that the way that user integration is valued, determines its actual impact.

\subsubsection{Theory and practice}

Researchers agree that user experience as a phenomenon designates the interaction experience with a product. Thus, user experience design needs the users to be integrated. Practitioners tend to agree that UX is a subjective and dynamic concept, influenced by several contextual factors. The majority of UX professionals is interested in UX to design better products, while academics are more interested in UX per se, as an object of study. Numerous differences observed between Industry and Academia clearly indicate that there is still a gap between both perspectives. A better integration of theories and practice should thus be a primary goal, undoubtedly leading to a win-win situation for both Academia and Industry. On the one hand, UX research should be taught to students better as they represent the next generation of UX practitioners. On the other hand, UX research should thrive on practice to better answer the needs and expectations of the UX industry and provide practitioners with solid and valid tools needed for user integration when assessing or designing for user experience.

There is a need for enhanced education and training. This also means that there is a need for a definition that would allow translating the concept into practice and better communicate on UX. One could have expected a better dissemination of UX research results into Industry over time. It seems however, this remains only partly achieved. The evolution of UXD methods and the better understanding of UX in general might lead to the thinking that the characteristics of the product per se are able to support UX in a consistent way. Methods for design, programming skills are competencies that designers learn during der education, but the domain specific knowledge needs to be acquired on the job. The ability to cooperate interdisciplinary with users and other experts in the field was emphasized as necessary.

\subsection{Challenges and limitations of the analysis}

Driven towards novelty and innovation, some terms used in the analysed papers tend to emerge as popular trends and fade away quickly without having been really analysed through the lens of empirical 
research. This exploratory study does not involve a random and representative sample. One has to be aware that several biases might have affected previous results and may affect the present ones, especially the fact that not all researchers submitted papers of their projects to the chosen conferences, may have done this after the selected period, or had been not accepted. Neither the number of people who potentially should have been invited to be part of this analysis nor the coverage of the target population are accurately known.

Every research design has strengths and weaknesses, however. The method chosen has clear advantages in the exploitability of the results. Because the analysis categories were developed across disciplines based on current contributions, the entire research field can actively tie in with central topics and reflect on them from a bird's-eye perspective in a broader context. One of the strengths of the selected conferences is the consideration of contributions from both theory and practice. As has been shown in the course of this research, different perspectives dominate in both areas, which are illustrated here and have been made accessible for a comprehensive analysis. By using an international sample, it is possible to depict reliably some overall trends within the field.

Nevertheless, many questions stay unanswered at both a theoretical and a methodological level. Several initiatives have been launched to structure and support the development of UX at an academic level (Law et al., 2007; Law et al., 2010). The results of the present study contribute to this objective. By trying to draw an accurate picture of the current situation of user integration in product development and building on that basis, it aims at better methodologies, frameworks and metrics for doing so. Further research should be done in order to present a target means matrix, which helps professionals to decide what, when, how, whereby and, finally, 'who' should be integrated in product development (Wallisch and Paetzold, 2017).

\section{Conclusion}

This study proves that for the user description, and thus for the analysis of the wishes and demands of the users, various methods and approaches focusing on different aspects such as the social context or specific personality traits are known and used. On closer inspection, however, it is becoming clear that due to the heterogeneity within the user groups, not only the analysis and description of users is necessary: the translation of the rather soft wishes of users into concrete product functions and parameters also requires methodological support. It seems even more important to provide powerful methods for validating user needs and requirements.

Although existing design models confirm the importance of integrating users into the process, the specific interaction between designer and user information is not constantly taken into account. Different philosophies and approaches have been offered for the development of user interfaces in general, such as for example participatory design, user-centred design, emotional design, compassionate design, et cetera. All these propose various ways of involving users in the design process and all of them stress the fact that access to user's experiences is central in the design process. Nevertheless, it is rarely taken into account that one also has to understand the underlying mindset that frames all of these experiences.

The main result of this research is the emphasis on the fact that user integration is not necessarily the same as the integration of users. It is important to be aware of the fact that the users contribute to product development processes in different phases in different roles. The analysis indicate that the designers want the users to contribute more in the informative and consulting tasks rather than to participate them really on the design process. On the other hand, it is known that participation in the early stages of development is helpful to get people engaged with the product. Therefore, it is necessary to educate both, the users for their roles within the collaboration process and the engineering designers in the methods of participative user integration.

By means of this integrational preliminary work, the uncertainty in dealing with the respective required implementation of user integration can be minimized considerably. Further research on the users view on their role as end user representatives and their participation in the design process activities should be investigated in more detail. A stronger exchange between science and practice is necessary for the preparation of appropriate action guidelines for fruitful user integration in product development, which leads to better user experience and, therefore, better products. 


\section{References}

Bosman, Y.M. (2005), Measuring the user participation construct. [online] ResearchGate. Available at: https://www.researchgate.net/publication/228401543_Measuring_the_user_participation_construct

Bruseberg, A. and McDonagh-Philp, D. (2001), "New product development by eliciting user experience and aspirations", International Journal of Human-Computer Studies, Vol. 55 No. 4, pp. 435-452. https://doi.org/10.1006/ijhc.2001.0479

Carroll, J.M. and Rosson, M.B. (2007), "Participatory design in community informatics", Design Studies, Vol. 28 No. 3, pp. 243-261. https://doi.org/10.1016/j.destud.2007.02.007

Cavaye, A.L.M. (1995), "User participation in system development revisited", Information \& Management, Vol. 28 No. 5, pp. 311-323. https://doi.org/10.1016/0378-7206(94)00053-L

Cooper, R.G. and Kleinschmidt, E.J. (1987), "New products: what separates winners from losers?", Journal of Product Innovation Management, Vol. 4 No. 3, pp. 169-184. https://doi.org/10.1111/1540-5885.430169

Damodaran, L. (1996), "User involvement in the systems design process - a practical guide for users", Behaviour \& Information Technology, Vol. 15 No. 6, pp. 363-377. https://doi.org/10.1080/014492996120049

DIN Deutsches Institut für Normung e.V. (2000), Human-centred design processes for interactive systems (ISO 13407:1999), Beuth Verlag GmbH.

DIN Deutsches Institut für Normung e.V. (2011), Ergonomics of human-system interaction - Part 210: Humancentred design for interactive systems (ISO 9241-210:2010), Beuth Verlag GmbH.

Fichter, K. (2005), "Nachhaltige Nutzerintegration im Innovationsprozess", In: Fichter, K., Paech, N. and Pfriem, R. (Ed.), Nachhaltige Zukunftsmärkte - Orientierungen für unternehmerische Innovationsprozesse im 21. Jahrhundert, Metropolis Verlag, Marburg, pp. 351-370.

Flick, U. (2009), An Introduction to Qualitative Research, 4th ed., Sage Publications Ltd., London.

Garrett, J.J. (2011), The Elements of User Experience: User-Centered Design for the Web and Beyond, 2nd Edition, New Riders, Pearson Education, Berkeley.

Glaser, B.G. and Strauss, A. (1967), The Discovery of Grounded Theory: Strategies for qualitative Research, Aldine Transaction, New Brunswick, London.

Hartwick, J. and Barki, H. (1994), "Explaining the role of user participation in information system use", Management Science, Vol. 40 No. 4, pp. 440-465. https://doi.org/10.1287/mnsc. 40.4 .440

Hassenzahl, M. (2003), "The thing and I: Understanding the relationship between user and product", In: Blythe, M., Overneeke, C., Monk, A.F. and Wright, P.C. (Eds.), Funology: From usability to enjoyment, Springer, Dortrech, pp. 31-42. https://doi.org/10.1007/1-4020-2967-5 4

Hassenzahl, M. (2010), Experience Design: Technology for All the Right Reasons, Synthesis lectures on HumanCentered Informatics, Morgan \& Claypool Publishers, Penn State University. https://doi.org/10.2200/S00261ED1V01Y201003HCI008

Hassenzahl, M. (2008), "User Experience (UX): Towards an experiential perspective on product quality", Proceedings of IHM'08 / the 20th Conference on l' Interaction Homme-Machine, Metz, France, September 25, 2008, ACM New York, pp. 11-15. https://doi.org/10.1145/1512714.1512717

Karapanos, E., Zimmermann, J., Forlizzi, J. and Martens, J.B. (2010), "Measuring the dynamics of remembered experience over time", Interacting with Computers, Vol. 22 No. 5, pp. 328-335. https://doi.org/10.1016/j.intcom.2010.04.003

Kim, J. and Wilemon, D. (2002), "Focusing the fuzzy front-end in new product development", R\&D Management, Vol. 32 No. 4, pp. 269-279. https://doi.org/10.1111/1467-9310.00259

Kujala, S. (2003), "User involment: a review of the benefits and challenges", Behaviour \& Information Technology, Vol. 22 No. 1, pp. 1-16. https://doi.org/10.1080/01449290301782

Kujala, S. (2008), "Effective user involvement in product development by improving the analysis of user needs", Behaviour \& Information Technology, Vol. 27 No. 6, pp. 457-473. https://doi.org/10.1080/01449290601111051

Lallemand, C., Gronier, G. and Koenig, V. (2015), "User experience: A concept without consensus? Exploring practitioners' perspectives through an international survey", Computers in Human Behavior, Vol. 43, pp. 3548. https://doi.org/10.1016/j.chb.2014.10.048

Law, E. L.-C., Roto, V., Hassenzahl, M., Vermeeren, A. and Kort, J. (2009), “Understanding, scoping and defining UX: a survey approach", Proceedings of CHI'09 / the ACM SIGCHI Conference on Human factors in computing systems, Boston, USA, April 4-9, 2009, ACM, New York, pp. 719-728. https://doi.org/10.1145/1518701.1518813

Law, E.L.-C. and van Schaik, P. (2010), "Modelling user experience - An agenda for research and practice", Interacting with Computers, Vol. 22 No. 5, pp. 313-323. https://doi.org/10.1016/j.intcom.2010.04.006 
Law, E.L.-C., van Schaik, P. and Roto, V. (2014), “Attitudes towards user experience (UX) measurement", International Journal of Human-Computer Studies, Vol. 72 No. 6, pp. 526-541. https://doi.org/10.1016/j.ijhcs.2013.09.006

Law, E.L.-C., Vermeeren, A., Hassenzahl, M. and Blythe, M. (2007), “Towards a UX Manifesto", Proceeding of BCS-HCI '07 / the 21st British HCI Group Annual Conference on People and Computers: HCI...but not as we know it, Vol. 2, Lancaster, UK, September 3-7, 2007, BCS Learning \& Development Ltd, Swindon, pp. 205206.

Lilien, G.L., Morrison, P.D., Searls, K.S., Sonnack, M. and von Hippel, E.A. (2002), "Performance assessment of the lead user idea-generation process for new product development", Management Science, Vol. 48 No. 8, pp. 1042-1059. https://doi.org/10.1287/mnsc.48.8.1042.171

Mahlke, S. (2008), User Experience of interaction with technical systems: Theories, methods, empirical results, and their application to the design of interactive systems, VDM Verlag, Saarbrücken, Germany.

McKeen, J.D., Guimaraes, T. and Wetherbe, J. (1994), “The relationship between use participation and user satisfaction: an investigation of four contingency factors", MIS Quarterly, Vol. 18 No. 4, pp. 427-451. https://doi.org/10.2307/249523

Meixner, H. (1995), Zum Einfluss partizipativer Entwicklungstechniken auf die Benutzerfreundlichkeit von Programmsystemen: Eine Feldstudie, Shaker, Aachen.

Norman, D., Miller, J. and Henderson, A. (1995), "What you see, some of what's in the future, and how we go about doing it: HI at apple computer", Proceedings of CHI'95 / the ACM Conference on Human factors in computing systems, Denver, Colorado, USA, May 7-11, 1995, ACM, New York, p. 155. https://doi.org/10.1145/223355.223477

Olsson, E. (2004), "What active users and designers contribute in the design process", Interacting with Computers, Vol. 16 No. 2, pp. 377-401. https://doi.org/10.1016/j.intcom.2004.01.001

Preece, J., Rogers, Y. and Sharp, H. (2002), Interaction design: Beyond human-computer interaction, John Wiley \& Sons, New York, NY.

Richards, L. (2015), Handling qualitative data: a practical guide, 3rd ed., Sage, London.

Roto, V., Law, E., Vermeeren, A. and Hoonhout, J. (2011), User experience white paper: Bringing clarity to the concept of user experience, Result from Dagstuhl Seminar on Demarcating User Experience, Finland. [online] Available at: http://www.allaboutux.org/uxwhitepaper.pdf (accessed 05.09.2017)

Thüring, M. and Mahlke, S. (2007), "Usability, aesthetics and emotions in human-technology interaction", International Journal of Psychology, Vol. 42 No. 4, pp. 253-264. https://doi.org/10.1080/00207590701396674

Veryzer, R.W. and Borja de Mozota, B. (2005), "The Impact of User-Oriented Design on New Product Development: An Examination of Fundamental Relationships*", The Journal of Product Innovation Management, Vol. 22 No. 2, pp. 128-143. https://doi.org/10.1111/j.0737-6782.2005.00110.x

Wallisch, A. and Paetzold, K. (2017), "User integration in design: applying social science research questions for successful participation management at every product development step", Proceedings of IDE $2017 /$ the 11 th International Workshop on Integrated Design Engineering, Magdeburg, Germany, April 5-7, 2017, pp. 39-48.

Wilson, S., Bekker, M., Johnson, P. and Johnson, H. (1997), "Helping and hindering user involvement - a tale of everyday design", Proceedings of CHI'97 / the ACM SIGCHI Conference on Human factors in computing systems, Atlanta, Georgia, USA, March 22-27, 1997, ACM, New York, pp. 178-185. https://doi.org/10.1145/258549.258699

Zhang, Z., Qingjin P. and Peihua G. (2015), "Improvement of User Involvement in Product Design", Procedia CIRP, Vol. 36, pp. 267-272. https://doi.org/10.1016/j.procir.2015.01.019

Anne Wallisch, Dipl.-Soz., M.A.

Bundeswehr University Munich, Institute for Technical Product Development

Werner-Heisenberg-Weg 39, 85577 Neubiberg, Germany

Email: anne.wallisch@unibw.de 